\title{
Peter Merseburger, Theodor Heuss. Der Bürger als
}

Präsident. Biografie

München : Pantheon-Verlag, 2014 (éd. orig. Deutsche Verlagsanstalt, 2012), 672 p., $16,99 €$.

\section{Marcel Tambarin}

\section{OpenEdition}

\section{Journals}

Édition électronique

URL : http://journals.openedition.org/ifha/8410

DOI : $10.4000 /$ ifha. 8410

ISSN : 2198-8943

\section{Éditeur}

IFRA - Institut franco-allemand (sciences historiques et sociales)

\section{Référence électronique}

Marcel Tambarin, "Peter Merseburger, Theodor Heuss. Der Bürger als Präsident. Biografie », Revue de I'IFHA [En ligne], Date de recension, mis en ligne le 01 février 2016, consulté le 22 septembre 2020. URL : http://journals.openedition.org/ifha/8410 ; DOI : https://doi.org/10.4000/ifha.8410

Ce document a été généré automatiquement le 22 septembre 2020

(CIFHA 


\section{Peter Merseburger, Theodor Heuss. Der Bürger als Präsident. Biografie}

München : Pantheon-Verlag, 2014 (éd. orig. Deutsche Verlagsanstalt, 2012), 672 p., $16,99 €$.

\section{Marcel Tambarin}

Figure tutélaire de la République fédérale, dont il fut l'un des membres fondateurs et le premier président de 1949 à 1959, Theodor Heuss a pourtant dû attendre quasiment le $50^{\mathrm{e} m e}$ anniversaire de sa disparition pour se voir consacrer une première biographie exhaustive, celle du journaliste Peter Merseburger, qui vient compléter celle relativement brève du directeur adjoint de la fondation Theodor Heuss, Ernst Wolfgang Becker (Theodor Heuss. Bürger im Zeitalter der Extreme, Stuttgart : Kohlhammer, 2011), et qui a elle-même été suivie entre-temps de la biographie tout aussi volumineuse de l'historien Joachim Radkau (Theodor Heuss, München: Hanser, 2013). Lui-même auteur de plusieurs biographies, en particulier sur son mentor Friedrich Naumann, mais aussi sur Justus Liebig et Robert Bosch, Th. Heuss a trouvé en Peter Merseburger un biographe attentif et attentionné, qui nous donne, après ses biographies de Kurt Schumacher et de Willy Brandt, un ouvrage qui brosse un portrait aussi vivant que détaillé de l'ancien président, tout en s'attachant à désarmer les jugements défavorables qui restent attachés à ce président de proximité que le politologue Arnulf Baring a pu qualifier de «personnage apolitique».

Les plus de 600 pages de la biographie s'ordonnent en dix chapitres chronologiques, et c'est ainsi que l'on voit défiler la vie, la carrière et l'oeuvre de Th. Heuss, depuis son enfance et sa jeunesse en Souabe, sous le signe des légendes de la Révolution de 1848; ses années d'études à Munich, où il cotoie des Kathedersozialisten comme son directeur de thèse Lujo Brentano; sa rencontre avec la figure-clé du libéralisme allemand Friedrich Naumann et sa collaboration à la revue Die Hilfe; son travail de journaliste pendant la Première guerre mondiale, en tant que rédacteur en chef de la NeckarZeitung à Heilbronn; sous Weimar, d'abord son double engagement de libéral-national comme professeur à la Hochschule Für Politik de Berlin et comme rédacteur des revues libérales Deutsche Politik, puis Die Deutsche Nation; puis, comme député au Reichstag et 
en particulier ses années de confrontation avec les nazis; ensuite, le vote des pleins pouvoirs à Hitler en 1933, suivi des années d'« immigration intérieure»; et enfin la période d'après 1945, à laquelle sont consacrés les trois derniers chapitres : le premier portant sur son retour en politique après 1945 , comme ministre de l'éducation de l'éphémère Land de Wurtemberg-Bade, comme dirigeant du nouveau parti libéral FDP et comme membre du Conseil Parlementaire de Bonn, au sein duquel il collabore à la rédaction de la nouvelle constitution; les deux derniers sur ses années de président d'abord élu contre Kurt Schumacher puis réélu sans concurrent dans une fonction à l'ombre de celle du chancelier, mais qu'il a su habiter en incarnant cette figure à la fois modeste et représentative de " citoyen président ».

Étant donné la longue vie et la longue carrière politique de Th. Heuss (1884-1963), socialisé sous la monarchie et déjà âgé de 30 ans en 1914, c'est aussi un panorama des courants et formations libérales que nous donne cette biographie, de la fin de l'empire jusqu'à la RFA en passant par la République de Weimar et le national-socialisme. Cette dernière période reste d'ailleurs la plus problématique pour Th. Heuss. Il a certes publié une des premières analyses du nazisme avec son livre Hitlers Weg. Eine historischpolitische Studie über den Nationalsozialismus, mais si Th. Heuss en a refusé la réédition après la guerre, sachant que le livre serait pris pour une relativisation du nazisme (bien qu'il ait lui aussi été livré aux flammes en 1933), c'est de fait que son approche était bien moins lucide que celle d'un Konrad Heiden, dont le livre Geschichte des Nationalsozialismus. Die Karriere einer Idee, également paru en 1932 n'a jamais été réédité, à la différence du premier qui a finalement eu cet honneur en 2008. Mais ce qui, du propre aveu de Heuss, reste une tache indélébile dans sa vie politique, c'est le vote des pleins pouvoirs à Hitler le 23 mars 1933. Quels que soient les arguments avancés par Th. Heuss lui-même après la guerre (il dira devant une commission d'enquête en 1947 que le vote des pleins pouvoirs ne changeait rien à une évolution qu'il jugeait inéluctable), il n'en reste pas moins, comme le rappelle honnêtement Merseburger en dépit de ses efforts pour expliquer le vote de Th. Heuss, qu'ils sont en contradiction avec le jugement des historiens et que ce vote entretient aujourd'hui encore une approche autrement plus critique du personnage de Th. Heuss (voir Dirk Hoeges, Theodor Heuss. Eine Stimme für Hitler, Köln : machiavelli edition, 2015). Il est vrai que la distance aidant, le jugement devient moins empathique, et P. Merseburger, lui-même né en 1928, considère que la génération actuelle n'aurait sans doute jamais élu président un homme comme Th. Heuss. Mais dans l'après-guerre, cette incarnation de l'histoire allemande et de ses turbulences, popularisée sous la figure débonnaire du Papa Heuss (que lui-même détestait du reste), a aussi contribué à décrisper l'Allemagne après le choc de la défaite, en substituant habilement la notion de « honte collective » à celle de " culpabilité collective ", et tout en s'opposant, bien au contraire, à ce qu'un trait soit tiré sous le passé. Et à ce titre à tout le moins, P. Merseburger peut légitimement conclure que Th. Heuss a été tout sauf un président apolitique.

$\mathrm{Au}$ final, rien de bien neuf cependant dans cette biographie, qui tient certes compte de l'état de la recherche (dont témoigne une bibliographie abondante bien que sélective), ainsi que des sources publiées (dont la correspondance et les journaux personnels abondamment cités), mais qui n'exploite pas d'archives nouvelles. Trois séries de photographies en noir et blanc totalisant plus de 60 reproductions viennent illustrer le propos, mais la présence d'une table chronologique aurait été tout aussi utile que l'index très fourni des noms propres. Soigneusement documentée, pondérée dans le 
jugement, écrite qui plus est d'une plume alerte et fluide, cette biographie de Th. Heuss n'en reste pas moins un ouvrage d'une lecture aussi agréable qu'instructive.

Vous trouverez la table des matières ici : http://d-nb.info/1050506324/04.

INDEX

Index chronologique : Époque contemporaine

Thèmes : Histoire des États et des pouvoirs

\section{AUTEUR}

MARCEL TAMBARIN

Université de Bourgogne Franche-Comté (Dijon) - ILCEA4/CERAAC (EA EA 7356) 